San Jose State University

SJSU ScholarWorks

Master's Theses

Master's Theses and Graduate Research

Fall 2011

\title{
The Effects of Self-Referencing on Mood and Information \\ Processing
}

Michael Mehler

San Jose State University

Follow this and additional works at: https://scholarworks.sjsu.edu/etd_theses

\section{Recommended Citation}

Mehler, Michael, "The Effects of Self-Referencing on Mood and Information Processing" (2011). Master's Theses. 4102.

DOI: https://doi.org/10.31979/etd.rbb2-sxfw

https://scholarworks.sjsu.edu/etd_theses/4102

This Thesis is brought to you for free and open access by the Master's Theses and Graduate Research at SJSU ScholarWorks. It has been accepted for inclusion in Master's Theses by an authorized administrator of SJSU ScholarWorks. For more information, please contact scholarworks@sjsu.edu. 


\title{
THE EFFECTS OF SELF-REFERENCING AND MOOD ON INFORMATION PROCESSING
}

\author{
A Thesis \\ Presented to \\ The Faculty of the Department of Psychology \\ San Jose State University \\ In Partial Fulfillment \\ of the Requirements for the Degree \\ Master of Arts \\ by \\ Michael Mehler \\ December 2011
}


(C) 2011

Michael Mehler

ALL RIGHTS RESERVED 
The Designated Thesis Committee Approves the Thesis Titled

THE EFFECTS OF SELF-REFERENCING AND MOOD ON INFORMATION PROCESSING

by

Michael Mehler

APPROVED FOR THE DEPARTMENT OF PSYCHOLOGY SAN JOSÉ STATE UNIVERSITY

December 2011
Dr. Arlene Asuncion
Department of Psychology
Dr. Cheryl Chancellor-Freeland
Department of Psychology
Dr. Clifton Oyamot
Department of Psychology 


\section{ABSTRACT \\ THE EFFECTS OF SELF-REFERENCING AND MOOD ON INFORMATION PROCESSING \\ by Michael Mehler}

Research in the area of attitude change has demonstrated that people can process a persuasive message in a systematic or heuristic manner. It has been shown that positive mood increases heuristic processing, whereas negative mood increases systematic processing. In the current study, we were interested in examining one factor that may increase happy people's ability or desire to systematically process a persuasive message, self-referencing. Self-referencing occurs when information is processed by relating it to oneself or one's personal experience. After a happy, neutral, or sad mood was induced, participants were exposed to a message with either self-referencing or no self-referencing in the content. Participants' attitude change toward the message was then assessed. Results showed that happy participants systematically processed only when the message was self-referencing, supporting our predictions. Results suggested that self-referencing has a considerable influence on mood and information processing and can serve as a motivational factor that increases happy people's desire to systematically process a persuasive message. 


\section{TABLE OF CONTENTS}

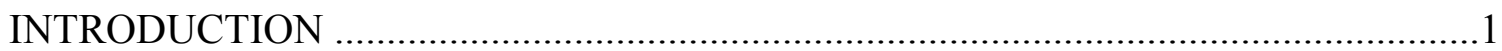

FACTORS AFFECTING INFORMATION PROCESSING ...................................4

EXPLANATIONS FOR MOOD'S EFFECTS ON PROCESSING $. . \ldots \ldots \ldots \ldots \ldots \ldots \ldots . .7$

SELF-REFERENCING AND MESSAGE PROCESSING ......................................11

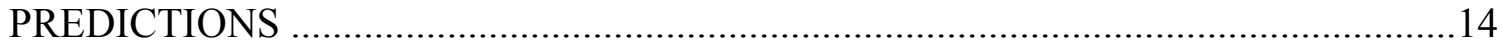

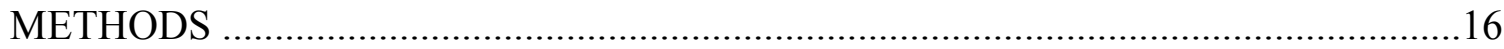

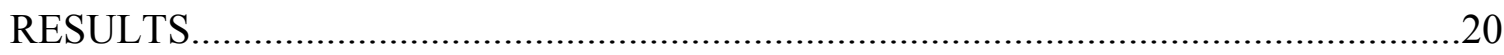

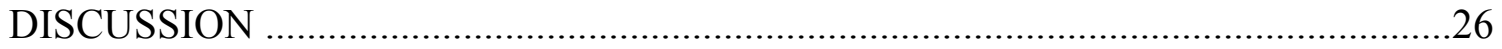

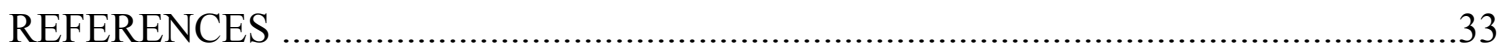

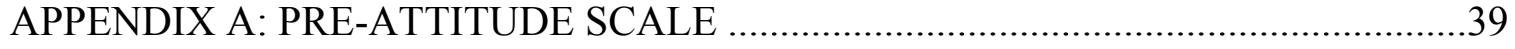

APPENDIX B: VIDEO PRE-TESTING ............................................................43

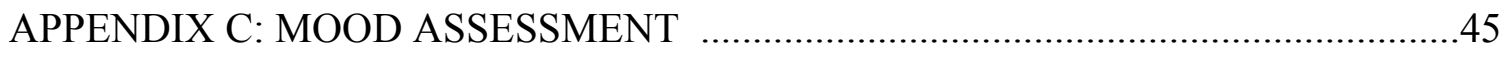

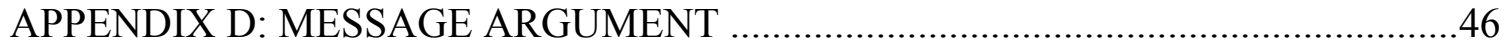

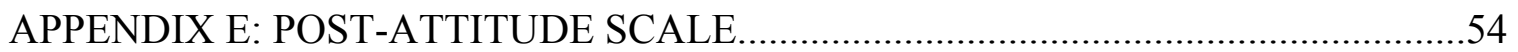




\section{LIST OF FIGURES}

Figure 1. Attitude change among participants in the neutral mood condition.................23

Figure 2. Attitude change among participants in the sad mood condition......................24

Figure 3. Attitude change among participants in the happy mood condition...................25 


\section{Introduction}

In general, research in the area of attitude change has demonstrated that people can process a persuasive message in a systematic or heuristic manner (Chaiken, 1980). Both conceptualizations consider message recipients as concerned with assessing the validity of the message's overall conclusion. The heuristic-systematic model (HSM; Chaiken, 1987) delineates the two basic modes by which perceivers may determine their attitudes and other social judgments (Chaiken, Liberman, \& Eagly, 1989). According to a systematic view, recipients apply significant cognitive effort in performing this task and actively attempt to comprehend and evaluate the message's arguments as well as to assess their validity in relation to the message's conclusion. In contrast, according to a heuristic view of persuasion, recipients exert comparatively little effort in judging message validity. Rather than processing argumentation, recipients may rely on more available information such as the source's identity or other non-related cues in deciding to accept a message's conclusion. In sum, heuristic processing makes minimal cognitive demands, whereas systematic processing requires cognitive ability and capacity (Chen \& Chaiken, 1999).

The heuristic-systematic model assumes that perceivers are guided in part by a "principle of least effort" (Chen \& Chaiken, 1999). That is, in the interest of economy, heuristic processing often predominates over more effortful systematic processing. Information processing, however, is often guided by motivational concerns beyond economy. Recognizing this, the heuristic-systematic model incorporates least-effort notions into its sufficiency principle, which claims that perceivers attempt to balance 
between minimizing cognitive effort on the one hand and satisfying their current motivational concerns on the other (Chaiken, Wood, \& Eagly, 1996). For example, perceivers who are motivated to determine accurate judgments apply as much cognitive effort as necessary and possible to reach a sufficient degree of confidence that their judgments will satisfy their accuracy.

When systematic processing occurs, the quality of message content becomes the primary determinant of the recipient's reaction to the message and consequently determines its persuasive success (Worth \& Mackie, 1987). Judgments formed on the basis of systematic processing are thus responsive to the actual content of the information (Chen \& Chaiken, 1999). For systematic processing to occur, people must be both motivated and possess the capacity to think (Chaiken et al., 1989). When personal interest is combined with a biased knowledge, systematic processing is most likely to occur (Petty \& Caccioppo, 1979).

On the other hand, a heuristic strategy has the economic advantage of requiring minimum cognitive effort. Heuristic processing entails the activation and application of judgmental rules or "heuristics" that are presumed to be learned and stored in memory. For example, "Expert" statements can be trusted," "Length implies strength," "Consensus opinions are always correct" (Chen \& Chaiken, 1999). However, a heuristic strategy may be a less reliable means of judging message validity. In the long run, recipients may sometimes reject message conclusions they might otherwise have accepted had they investigated the time and effort to receive and scrutinize argumentation (Chaiken, 1980). 
The critical measure of whether systematic processing occurs in a persuasive situation is whether message recipients are differentially persuaded by strong and weak arguments (Worth \& Mackie, 1987). For example, Bless, Bohner, Schwarz, and Strack (1990) found that individuals in a positive mood were less persuaded by strong arguments than those in a neutral or sad mood. Strong arguments provoke thoughts favorable to the message and lead to persuasion, while weak arguments cause counter arguing and little persuasion (Chaiken, 1980). 


\section{Factors Affecting Information Processing}

\section{Motivation}

People can engage in information processing for a variety of motivational (e.g. consistency motivation, reactance, self-esteem maintenance) and ability driven (e.g. one sided-knowledge on a topic, mood) reasons (Petty, Wegener, \& Fabrigar, 1997). But when will recipients employ a systematic rather than a heuristic processing strategy? One factor that may influence a recipient's decision-making process is involvement with the message. Systematic processing should be employed when recipients perceive that it is important to formulate a highly accurate judgment. Recipients are more likely to hold such a perception when they receive messages on personally important topics or when recipients feel that their opinion judgments have important consequences for themselves or for others (Chaiken, 1980). When personal relevance is combined with a vested interest, then the thorough processing induced by the relevance is likely to produce systematic processing (Petty et al., 1997). For example, Liberman and Chaiken (1992) found that women who were personally vulnerable to a threatening message engaged in more systematic processing of it than women who were not personally vulnerable to the threat. Similarly, Hutton \& Baumeister (1992) found that placing message recipients in front of a mirror (enhancing self-awareness) increased their thoughtful resistance to a message that was personally important but not to a message that was not. However, when asked for an opinion on an unimportant topic or when one's opinion judgment is perceived as insignificant, recipients may give economic concerns greater weight and employ a heuristic processing strategy (Chaiken, 1980). A practical perspective suggests 
that recipients employ a systematic strategy when reliability concerns outweigh economic concerns and a heuristic strategy when economic concerns predominate.

\section{Mood}

Another factor that may influence a recipient's decision-making process is mood. Mood can play a significant role in how people perceive the world around them as well as the strategies used when processing incoming information. Early research on the topic primarily focused on describing how different mood states affected the level of argument processing (Petty, Fleming, Priester \& Feinstein, 2001;Schwarz \& Bless, 1991). It was discovered in general that individuals in good moods tended not to elaborate arguments extensively, did not differentiate strong and weak messages, and were more persuaded by peripheral appeals relative to people in neutral or sad moods (Bless, Bohner, Schwarz \& Strack, 1990; Mackie \& Worth, 1989; Sinclair, Mark, \& Clore, 1994; Worth \& Mackie, 1987). Conversely, people in sad moods tended to engage in more elaboration, to react differentially to strong and weak arguments, and to respond to central rather than peripheral appeals. When processing information, it has been found that relative to people in a neutral mood, people experiencing a positive mood prefer simple, intuitive solutions to problems, rely on judgment heuristics, use broad rather than specific categories in classification tasks, and make decisions both more quickly and on the basis of less information (Isen \& Daubman, 1984). Positive moods appear to promote global, flexible, intuitive, and holistic information processing (Isen, Ashby \& Turken, 1999; Isen, Labroo \& Durlach, 2004), where negative moods, in contrast, have been associated with more systematic, narrow, focused, and analytic forms of processing (Schwarz \& Clore, 
1996). Overall, it has been shown that positive mood increases heuristic processing, whereas negative mood increases systematic processing. 


\section{Explanations for Mood's Effects on Processing}

\section{Cognition}

More recent work in the area has attempted to document the various psychological mechanisms responsible for the typical mood-persuasion outcomes (Sinclair, Moore, Melvin, Soldat \& Lavis, 2010). One explanation for these findings is cognitive in nature. According to a cognitive approach, good moods limit processing capacity, reducing the availability for other processing tasks and resulting in the use of heuristics (Mackie \& Worth, 1989). Mood may also function as a distraction, interfering with the ability to engage in careful elaborative processing (Petty \& Brock, 1981). For example, happiness is assumed to restrict processing capacity because it increases the availability of positive thoughts and diverse associations in memory. This increased availability of positive thoughts and diverse ideas may therefore create a complex cognitive context for individuals experiencing a positive mood. This complex cognitive context in turn might interfere with happy individuals' ability to allocate the attention necessary to perform simultaneous processing tasks (Mackie, Worth \& Asuncion, 1990). Alternatively, happiness signals to a person that a situation is safe and less effortful information processing is needed, while sadness signals that a situation is problematic, requiring a more attentive, effortful form of cognitive processing (Schwarz, 1990; Schwarz \& Clore, 1983). Alternatively, sadness may decrease careful processing because being sad may lead individuals to think more about their moods (Ellis \& Ashbrook, 1988) or to find an explanation for the cause of their mood (Schwarz \& Clore, 1988). 


\section{Motivation}

Another possible explanation for the effects of mood on information processing is motivational in nature and deals with the experience of being in a good mood. A person in a good mood is likely to avoid systematic problem solving that could decrease the experience of positive affect, while people in sad moods are motivated to engage in careful information processing to alleviate or distract from their current negative feelings (Schwarz, 1990; Sinclair \& Mark, 1992, Sinclair et al., 2010). People generally strive to maintain or attain positive mood states and are most likely to attend to information that is uplifting, positive and rewarding and least likely to attend to messages that may spoil a good mood (Wegener \& Petty, 1994; Das \& Fennis, 2008). In both cases, happiness reduces extensive information processing because it decreases people's desire to process carefully (Asuncion \& Lam, 1995). Because extensive thinking about a problem has been found to be stressful and effortful, people in positive moods might be thought of as motivated to avoid this kind of cognitive effort in order to maintain their good mood (Janis \& Mann, 1977). While attempting to maintain their rewarding good mood, people in a positive mood may expose themselves to positively toned material and avoid negatively toned material (Isen \& Simmonds, 1978). A good mood may also increase feelings of confidence in relying on general, internal knowledge structures, including stereotypes and heuristics (Isbell, 2004). Consequently, the use of judgment heuristics, the ability to make good decisions without a lot of effort, by people experiencing a positive mood may reflect a lack of motivation to process extensively (Worth \& Mackie, 1987). 
On the other hand, sadness is argued to increase the desire for careful processing in order for the individual to try to change or reduce an unpleasant mood. For example, sad individuals may want to engage in careful processing, especially of pleasant or agreeable information (Isen, 1984). If feeling sad informs individuals of a threat in their environment, they may increase processing to understand the nature of this potential problem (Schwarz, 1990). Both possibilities result in sadness increasing deliberate information processing.

These cognitive and motivational consequences suggest that both happiness and sadness influence the extensive processing of persuasive messages. Happiness disrupts careful, elaborative processing either for cognitive and or motivational reasons (Asuncion \& Lam, 1995). However, the processing consequences of sadness differ depending on whether cognitive or motivational factors underlie its effects. According to cognitive approaches, sadness acts similarly to happiness and decreases extensive information processing. Motivational approaches, in contrast, argue that the effects of sadness are unlike those of happiness and suggest that feeling sad increases the deliberate processing of information.

In our study, we were interested in looking at another possible motivational factor that may increase happy people's desire to systematically process a persuasive message; that is, the self-referencing of the message itself. Self-referencing occurs when information is processed by relating it to oneself (e.g., one's own personal experience). Self-referencing can be described as a processing of information relating to the selfstructure or aspects of it (Burnkrant \& Unnava, 1995). This process may be encouraged 
by advertising persuasive messages that address the audience directly and introduces experiences to which it can relate. 


\section{Self-Referencing and Message Processing}

The self is considered a highly organized, complex memory structure that contains knowledge gained over a lifetime. As a result, when processing words or phrases there are more potential connections between those connected to the self and structures in memory (Burnkrant \& Unnava, 1995). This availability of more potential connections between the incoming information and memory facilitates elaboration of the incoming information. It has been found that performance of a self-referencing task rather than some other task, such as a semantic task, when processing words or phrases, leads to greater recall of those words or phrases (Bellezza, 1984; Brown, Keenan \& Potts, 1986; Rogers, Kuiper \& Kirker, 1977). For example, Rogers, Kuiper, and Kirker (1977) presented words to participants who had to make a yes or no judgment for each one. They found better recall for words accompanied by a question such as "Does this word describe you?" in comparison to words accompanied by a question such as "Does this word mean the same as honest?" The self-reference task resulted in better recall of the presented words than did simple semantic processing.

Similar results should occur when participants are induced to relate message arguments to aspects of themselves. For instance, addressing people directly and reminding them of their past experiences should increase the availability of those experiences. This increased availability of one's own experiences should in turn lead to an increase in self-related cognitive responding (i.e., the generation of thoughts about one's experiences). 


\section{Elaboration Likelihood Model}

According to Petty and Cacioppo's (1986a, 1986b) elaboration likelihood model of persuasion, recipients reading persuasive messages may either elaborate the content message (central route to persuasion), or rely on simple cues that are unrelated to the message's content, such as the communicator's prestige or likableness (peripheral route to persuasion). If the central route to persuasion is employed, the resulting attitude change is a function of the recipients' cognitive responses to the persuasive message. In other words, the more thoughts that come to mind that support the position advocated in the message, the more pronounced the attitude change would be (Bless et al., 1990).

\section{Effects of Self-Referencing}

Burnkrant and Unnava (1989) found that the effect of self-referencing depends on whether strong or weak message arguments are employed. In their high self-referencing condition, a strong arguments message was more persuasive than a weak arguments message; but in their low self-referencing condition, strong and weak arguments message did not differ in persuasiveness. The Burnkrant and Unnava (1989) findings suggest that self-referencing increases elaboration of message arguments, and this increased elaboration leads to more persuasion when message arguments are strong. When the information is favorable, we expect attitudes toward the information to be more favorable under high self-referencing than under low self-referencing conditions. There is evidence to support these predictions. Debevec and Iyer (1988) and Debevec and Romeo (1992) found that when participants were exposed to messages to which they could relate, their 
attitudes toward advertised products were more positive than when the ads did not facilitate personal relatedness.

Our main research question seeks to examine one factor that may lead participants in a positive mood to carefully process a persuasive message: self-referencing. Specifically, we were interested in the impact that positive and sad mood have on the processing of persuasive communications. We propose that through the manipulation of mood under different self-reference conditions, more theoretical insight can be obtained regarding mechanisms responsible for observed mood effects in the persuasion literature.

The study consisted of three independent variables: mood (positive, neutral, and sad), self-referencing (self-referencing or non-self referencing), and strength of argument (weak or strong). Participants' mood was induced through one of our three mood manipulations before reading a self or non-self-referencing argument in a strong or weak context. After message presentation, the main dependent measure, participants' attitude judgments, was assessed.

To test our hypotheses, participants were told that the study was intended for measuring college students' attitudes regarding public issues. They were then surveyed on their attitude regarding which they believed was healthier, bottled water or tap water. After a neutral, happy, or sad mood had been induced with the five-minute video mood manipulation, participants read a persuasive message about bottled water. Participants were exposed to either a strong or weak message, with self-referencing or no selfreferencing in the message content. Participants' attitude change toward the bottled versus tap water argument was assessed. 


\section{Predictions}

\section{Neutral Mood Condition}

Our first prediction was that neutral mood participants would process both the self-referencing and non-self-referencing message systematically. We assumed that findings in the neutral mood condition would most resemble those present in previous information processing studies in which no mood was induced (Worth \& Mackie, 1987, Isen \& Daubman, 1984). Therefore, participants in a neutral mood were expected to engage in systematic processing, resulting in attitude change that would favor the strong message more than the weak message in both the self-referencing and non-selfreferencing conditions.

\section{Sad Mood Condition}

Our second prediction was that participants in the sad mood condition would process both the self-referencing and non-self-referencing message systematically. This prediction was based on the implication that sadness increases careful information processing because of motivational factors (Asuncion \& Lam, 1995). As a result, we assumed that sad participants' attitude change would favor the strong message more than the weak message in both the self-referencing and non-self-referencing message.

However, it is also possible that sad mood could decrease systematic processing. As mentioned, processing consequences of sadness differ depending on whether cognitive or motivational factors underlie its effects (Asuncion \& Lam, 1995). Sadness may function similarly to happiness and cause a decrease in information processing. If this is the case, we expected sad participants to only process the self-referencing message 
and not non-self referencing message. If this possibility was found, sad participants' attitude change would favor the strong message more than the weak message in only the self-referencing message.

\section{Happy Mood Condition}

Our final prediction was that participants in the happy mood condition would systematically process only the self-referencing message. Although happiness disrupts careful, elaborative processing for cognitive and/or motivational reasons, we believed that because the message was personally directed at happy participants by way of selfreferencing, they would be more likely to systematically process the message. Therefore, participants' attitude change was expected to be higher in response to the strong arguments than to the weak arguments in the self-referencing condition only. In contrast, happy participants exposed to the non-self-referencing message were expected to show no signs of systematic processing. 


\section{Methods}

\section{Participants and Design}

Three hundred and eight psychology undergraduates were recruited from the experimental pool at San Jose State University. The experiment was described as a student attitude and information processing study. Students voluntarily participated in order to fulfill a course requirement in their introductory psychology course.

Participants were randomly assigned to the cells of a 3 (neutral, happy, or sad mood) $\times 2$ (self-referencing or non-self-referencing) x 2 (strong or weak argument) between-participants factorial design. Participants were run in groups of 5-8 at a time. The main dependent variable was participants' attitude change towards the various messages. Attitude change was a pre and post measure of participants' attitude in regards to the bottled water versus tap water argument.

\section{Procedures}

Participants were told they would be taking part in an experiment evaluating college students' attitudes and how they process information about messages. Participants were told that they would be given a survey about their attitudes on public issues, watch a video, rate their opinions on the video, read a message, and then rate their attitude on that message. Demographic sheets were given to each participant. The two persons administering the experiment introduced themselves and explained that they were working on different studies for the same lab, but combining the separate experiments into one hour of research time for economical reasons. This two-experiment ruse was used to separate the mood induction of the study from the information processing part of 
the study, ensuring that participants remained unaware that the purpose of the experiment involved examination of their mood state. "Researcher 1" administered the first part of the experiment. Participants were given five minutes to complete the public issues survey (Appendix A). This survey measured participants' attitude on bottled water versus tap water before the mood induction. After participants completed the survey, they were informed that the lab was also pre-testing some videos that would be used in another experiment. After the video, participants were asked to fill out a survey assessing their impressions of the video. This survey served as the mood manipulation check (Appendix B). Once completed, "Researcher 1" left the room, and "Researcher 2" administered the second part of the experiment. "Researcher 2" asked participants to take part in the main research project, which assessed how people process different kinds of messages. Participants were given five minutes to read the message about bottled versus tap water, which was either strong or weak in content with self or non-self-referencing. All messages can be found in Appendix D. After participants read the message, they filled out the post-message survey (Appendix E), assessing their attitude change on bottled water versus tap water issue. To ensure that self-referencing was effective, we included a manipulation check in this questionnaire. This manipulation check consisted of two questions, which assessed how participants perceived the message to relate to them directly. Similarly, an argument quality manipulation check consisting of two questions was included in this questionnaire, which assessed participants view on the strength of the argument. 


\section{Mood Manipulation - Pretesting}

The current study induced mood through the use of three 5-minute video clips. Sad mood was induced with a video clip showing events from September 11. The video used for inducing neutral mood explained the Washington Memorial and its history. The video used for inducing positive mood consisted of a clip from "Saturday Night Live." The effectiveness of the mood manipulation was pretested using an additional 35 participants not involved in the actual study. Pretest participants viewed one of three videos inducing either a sad, neutral, or positive mood. Participants' responses to three items assessing their mood after watching the videotape were averaged to form a single index of mood. The index consisted of three items rated on a likert scale ranging from 1 to 7 . The three items were: "How did this video clip make you feel? $(1=$ very sad, $7=$ very happy), "How would you describe your current feelings?" ( 1 = very bad, 7 = very good), "What is your present mood?" ( 1 = very negative, $7=$ very positive $)$. Results of this pretesting indicated that as intended, participants who watched the funny videotape reported feeling happier $(M=6.03)$ than participants who watched the neutral videotape $(M=4.67)$ and participants who watched the sad videotape $(M=2.09), \mathrm{F}(2,32)=66.21$, $p<.0001$. A tukey post hoc comparison indicated that mood indices of both happy and sad participants differed from those of neutral mood participants $(\mathrm{p}<.0001)$ as well as from one another $(p<.0001)$. Pretest results suggested that presentation of the videotapes was successful in inducing a neutral, happy, or sad mood state. 


\section{Dependent Measures}

The main dependent variable was participants' attitude change towards the various messages. To assess attitude change, participants' opinion on bottled versus tap water was measured before and after they read the persuasive message. Participants were asked to rate their opinion towards the following statement before they read the message: "Drinking tap water is healthier than drinking bottled water." Participants rated their opinion on this issue on a 7-point likert scale: "What is your opinion on this issue?" $(1=$ strongly disagree, 7 = strongly agree). The post-message opinion stated, "After reading the paragraph, what is your opinion on the argument that tap water is healthier than bottled water?" ( 1 = strongly disagree, 7 = strongly agree $)$. Participants rated their opinion on a 7-point likert scale. All dependent measures can be found in Appendix F. 


\section{Results}

\section{Mood Manipulation}

Participants' responses to the three items assessing their mood after watching the videotape were averaged to form a single index of mood (Cronbach's $\alpha=.88$ ). The index consisted of three items rated on a likert scale ranging from 1 to 7 . The three items were: "How did this video clip make you feel? ( 1 = very sad, 7 = very happy), "How would you describe your current feelings?" (1 = very bad, 7 = very good), "What is your present mood?" (1 = very negative, 7 = very positive). This index was analyzed in a 3 (neutral, happy, or sad mood) x 2 (self-referencing or non self-referencing) x 2 (strong or weak argument) between-participants analysis of variance (ANOVA). Results indicated that as intended, participants who watched the funny videotape reported feeling happier $(M=$ 5.26) than participants who watched the neutral videotape $(M=4.39)$ and participants who watched the sad videotape $(M=2.99), \mathrm{F}(2,296)=186.22, p<.0001$. A Tukey post hoc comparison indicated that mood indices of both happy and sad participants differed from those of neutral mood participants' $p s<.0001$ as well as from one another $p<$ .0001 . Presentation of the videotapes was therefore successful in inducing a neutral, happy, or sad mood state.

\section{Self-Referencing}

Participants' responses to the two items assessing the use of self-referencing in the message were averaged to form a single index of self-referencing (Cronbach's $\alpha=$ .72). The index consisted of two items rated in a likert scale ranging from 1 to 7 . The items were: "How much does the language in this paragraph refer to you "you" directly?" 
$(1=$ not very much, 7 = very much so $)$, and "This paragraph seemed to relate to me personally, as a student at San Jose State University" ( $1=$ strongly disagree, 7 = strongly agree). This index was analyzed in a 3 (neutral, happy, or sad mood) x 2 (selfreferencing or non-self-referencing) x 2 (strong or weak argument) between-participants analysis of variance (ANOVA). Results indicated that as intended, participants perceived the self-referencing message to relate to them more directly $(M=4.79)$ than the non-selfreferencing message $(M=4.16), \mathrm{F}(1,296)=17.37, p<.0001)$, confirming the validity of this manipulation.

\section{Argument Quality}

Participants' responses to the two items assessing the strength of the arguments in the message were averaged to form a single index of argument quality (Cronbach's $\alpha=$ .90). The index consisted of two items rated on a likert scale ranging from 1 to 7 . The items were "How would you rate the strength of this paragraph?" $(1=$ weak, $7=$ strong $)$, and "How convincing is this paragraph?" (1 = not at all convincing, 7 = convincing). This index was analyzed in a 3 (neutral, happy, or sad mood) x 2 (self-referencing or nonself-referencing) x 2 (strong or weak argument) between-participants analysis of variance (ANOVA). Results indicated that as intended, participants perceived the strong messages to contain stronger arguments $(M=5.35)$ than the weak messages $(M=3.76), \mathrm{F}(1,296)$ $=105.57, p<.0001$, confirming the validity of this manipulation.

\section{Attitude Change}

The analysis of primary interest concerns the attitude change toward the position advocated in the persuasive message from a comparison of each participant's premessage 
and postmessage position on the issue. To directly test the hypotheses, separate 2 (selfreferencing or non-self-referencing) x 2 (strong or weak argument) ANOVAs were conducted within each mood condition.

Neutral mood condition. Participants in a neutral mood were expected to systematically process both the self-referencing and non-self-referencing messages. Thus, we expected to replicate the typical information processing effect in the neutral mood condition. Results indicated that the main effect for argument quality within a neutral mood was significant $F(1,115)=10.09, p<.002$. Participants in a neutral mood showed more attitude change towards strong arguments $(M=1.74)$ than the weak arguments $(M=$ .67) when the message was self-referencing $\mathrm{F}(1,59)=5.03, p<.03$. Further, results indicated participants showed more attitude change towards strong arguments $(M=1.63)$ than weak arguments $(M=.61)$ when the message was non-self-referencing $\mathrm{F}(1,56)=$ $5.09, p<.03$. The results from this analysis indicate that as predicted, participants in a neutral mood showed evidence of systematic processing towards both the self-referencing and non-self-referencing messages. These analyses support previous research mentioned earlier as well as our own predictions. 


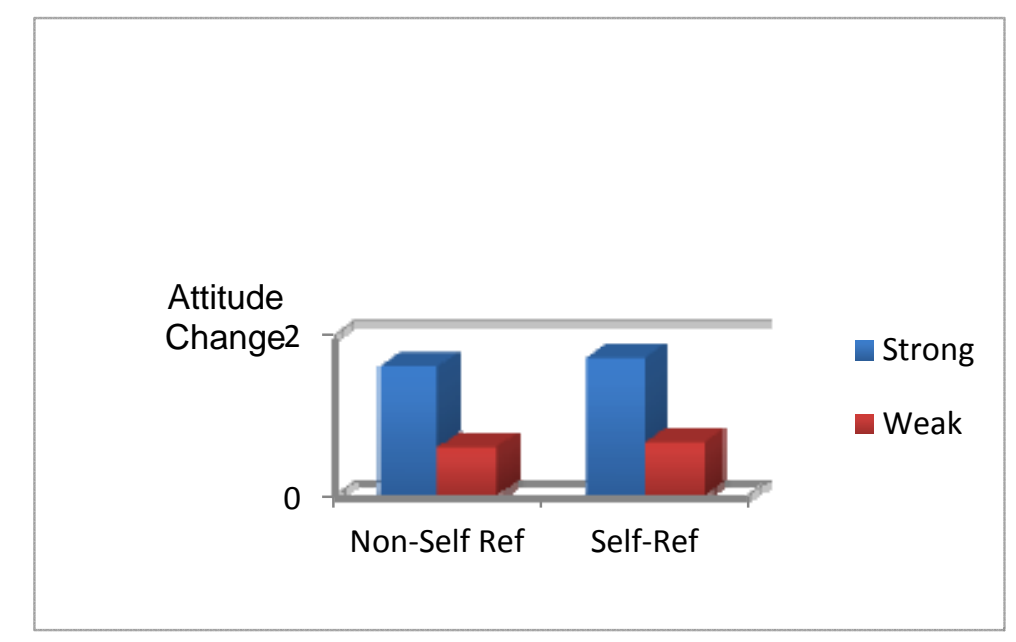

Figure 1. Attitude change among participants in the neutral mood condition

Sad mood condition. Although we expected participants in the sad mood condition to systematically process both the self-referencing and non-self-referencing messages, our alternate prediction suggested that sad mood could decrease systematic processing, leaving sad participants to only process self-referencing messages. The main effect for argument quality within the sad mood condition was not significant $F(1,82)=$ $1.88, p<.17$. Our results indicated a significant two-way interaction between selfreferencing and argument quality, $\mathrm{F}(1,44)=5.05, p<.03$. Results from this analysis indicated that participants in a sad mood showed more attitude change towards a strong $\operatorname{argument}(M=1.44)$ than a weak argument $(M=.21)$ when the message was selfreferencing. However, participants did not show more attitude change towards a strong $\operatorname{argument}(M=1.26)$ than a weak argument $(M=1.43)$ when the message was non-selfreferencing $\mathrm{F}(1,38)=5.09, p<.77$. These results indicated that sad participants processed systematically when the message was self-referencing, but not when the 
message was non-self-referencing, supporting our alternate prediction and previous research that sadness could actually decrease systematic processing.

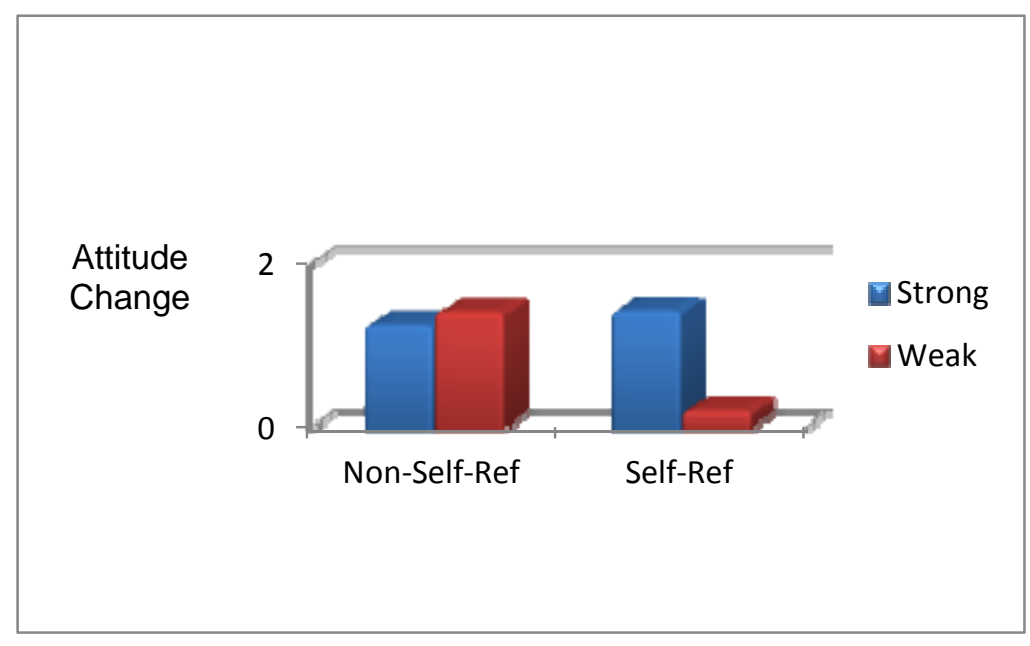

Figure 2. Attitude change among participants in the sad mood condition.

Happy mood condition. Participants in the happy mood condition were expected to systematically process only when exposed to the self-referencing message, and not the non-self-referencing message. If happiness decreases systematic processing, we expected happy participants to employ systematic processing only when the message is selfreferencing in context. Where previous research suggests that people in a happy mood do not process information systematically, we expected self-referencing to serve as a means to help participants process information more carefully. Results indicated a significant two-way interaction between self-referencing and argument quality, $\mathrm{F}(1,48)=.14 .42, p$ $<.0001$. Results from this analysis indicated that participants showed more attitude change towards a strong argument $(M=2.57)$ than a weak argument $(M=.70)$ when the message was self-referencing, indicating systematic processing. Further, and as predicted, happy participants did not show more attitude change towards strong 
arguments $(M=2.23)$ than weak arguments $(M=1.33)$ in the non-self-referencing arguments $\mathrm{F}(1,51)=2.66, p<.11$, indicating heuristic processing. These analyses supported our prediction that happy participants would systematically process both the strong and weak argument only when it was self-referencing in context.

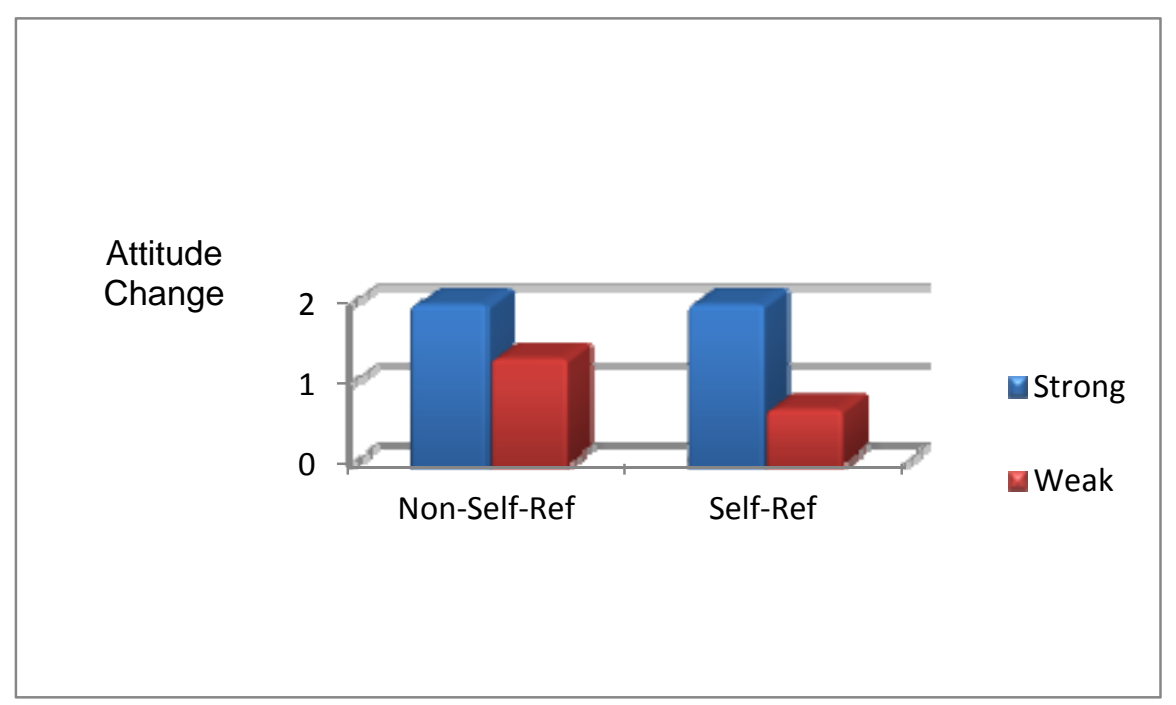

Figure 3. Attitude change among participants in the happy mood condition 


\section{Discussion}

The purpose of this study was to examine one factor that may lead participants in a positive mood to carefully process a persuasive message: self-referencing. Specifically, we were interested in the impact that positive and sad mood have on the processing of persuasive communications and how to promote systematic processing through the use of self-referencing. We proposed that through the manipulation of mood under different self-reference conditions, more theoretical insight could be obtained regarding mechanisms responsible for observed mood effects in the persuasion literature.

The results of this study provided evidence that self-referencing has the ability to guide participants in a positive mood to systematically process a persuasive message. The critical measure of systematic processing was whether message recipients were differentially persuaded by strong and weak arguments. Happy participants showed more attitude change towards a strong argument than a weak argument when the message was self-referencing, but did not show more attitude change towards strong arguments than weak arguments when the message was non-self-referencing. These results indicated that happy participants were able to distinguish between strong and weak arguments when the message was directed at them personally, via self-referencing, but not when the message was non-self-referencing. Because happy participants were able to make the distinction between strong and weak arguments only when the message was self-referencing indicated systematic processing and suggests that self-referencing has a considerable influence on mood and information processing. 
The effectiveness of happy people to distinguish between strong and weak arguments supports our hypothesis that self-referencing can serve as a motivational factor that increases happy people's desire to systematically process a persuasive message. Where previous research shows that people experiencing a happy mood cannot carefully process information, we found that by relating the message personally, happy participants were able to avoid heuristic processing and apply significant cognitive effort to systematically process the message. Our results suggest that it was the use of selfreferencing in the message that motivated happy participants to systematically process.

To provide support for our predictions, it was necessary to replicate previous research regarding how people in different mood states process information. Participants in a neutral mood demonstrated evidence of systematic processing by showing more attitude change towards strong arguments than weak arguments when the message was self-referencing, as well as non-self-referencing. The results from this analysis indicate that as predicted, participants in a neutral mood systematically processed both the selfreferencing and non-self-referencing messages. This result supports previous findings that people in a neutral mood engage in systematic processing when processing persuasive messages (Worth \& Mackie, 1987, Isen \& Daubman, 1984).

As predicted in our alternate prediction, sad participants systematically processed when the message was self-referencing, but not when the message was non-selfreferencing. This is an indication that sadness decreased participants' ability to systematically process information. Previous research suggests that sadness may decrease careful processing because being sad leads individuals to think more about their 
mood, which in turn may result in less available capacity allocated to the processing task (Ellis \& Ashbrook, 1988). Therefore, sad participants in our study may not have had the cognitive ability or capacity to concentrate on processing the persuasive message because they were instead evaluating why they felt sad, or how to alleviate their feelings of sadness. Although the results do not support our predictions entirely, previous research provides a potential explanation.

Although it is not possible to identify precisely why sad participants may or may not process persuasive messages carefully, the important finding was that sad participants processed the self-referencing argument systematically. This result indicated that selfreferencing was as effective for sad participants as for happy participants. Although we predicted sad participants would systematically process both strong and weak selfreferencing and non-self-referencing messages, we have indirectly found additional support for the effectiveness of self-referencing. Because sad participants in our study appeared to have experienced the same processing capabilities as happy participants and systematically processed the message only when it was self-referencing, we believe this provides additional evidence that self-referencing increased careful message processing.

Where previous research has shown that happiness disrupts careful processing, we have found an effective tool in self-referencing that can promote systematic processing of persuasive information in people experiencing a happy mood. Because happy participants were able to systematically process when the message was directed at them personally, we are more likely to believe that the inability of people in a happy mood to systematically process information is motivational in nature rather than a cognitive 
deficit. Extensive thinking about a problem has been found to be stressful and effortful and people in positive moods are thought of as motivated to avoid this kind of cognitive effort in order to maintain their good mood (Janis \& Mann, 1977). However, our results indicate that self-referencing may be the motivational factor that prompts people to engage in the cognitive effort required when processing a persuasive message. It appears that when the audience is highly involved or motivated, they will use a direct route to systematically process the message, provoking and relying primarily on their cognitive evaluations of the message. In contrast, the happy participants exposed to the non-selfreferencing condition did not perceive the messages as being directly targeted at them and were therefore relatively less motivated, most likely leading to the heuristic route of message processing.

\section{Practical Implications}

The use of self-referencing in persuasive message processing can serve as an essential instrument in practical settings. Our findings that self-referencing may be the motivational factor that prompts systematic processing can be of significance in many areas where persuasive communications are applied. Particularly, in the health domain, where persuasive messages may be designed to prevent illness, strategies that make individuals more capable of processing information could be exceptionally beneficial. For example, recent findings suggest that a positive mood promotes systematic processing of negative information when the information is relevant to the self (Raghunathan \& Trope, 2002). Raghunathan \& Trope (2002) found that the induction of a positive mood in high caffeine consumers enhanced recall of negative information 
about caffeine consumption. This finding demonstrated that a positive mood could promote systematic processing of self-threatening health facts and that positive mood acted as a resource, enabling people to elaborate more on negative but useful information.

Another set of recent findings showed that a positive mood increased systematic processing of unpleasant information only when the information pertained to the self. These results suggested that systematic processing was prompted by a heightened vigilance toward self-relevant, aversive stimuli. Therefore, a positive mood may provide individuals with the resources to deal with the psychological costs associated with the systematic processing of self-threatening information (Das \& Fennis, 2008).

These recent findings raise an interesting and relevant point in relation to the present study. It is important to note that we did not assess how often participants drank bottled or tap water. Because our main interest was self-referencing and its ability to prompt systematic processing, we were more interested in whether or not the message was self-referencing and less concerned with whether or not the information in the message was perceived as negative or positive. However, the message in the current study was balanced to include both positive and negative health information. For example, the message states that "DEHP is a cancer-causing agent found in plastic water bottles" but also states that "you are protected from this dangerous chemical when you drink tap water because the U.S. government regulates DEHP in all public water.” Therefore, participants' perception of the message being "self-threatening" is dependent on whether or not, or how often, they consume bottled or tap water. Although we measured if the messages were perceived as self-referencing, we did not assess whether 
or not these facts were perceived as "self-threatening," which appears to provide additional motivation to happy participants when processing persuasive messages. Nonetheless, it is possible that the participants in our study perceived the information in the message to be threatening health facts, resulting in a heightened awareness, which prompted systematic processing.

In conclusion, it appears that when self-referencing information is made available, individuals face a motivational dilemma. How individuals respond to this dilemma seems to be contingent upon whether the message being processed has positive or negative connotation. Specifically, it appears that when the information is negative and self-relevant, individuals experiencing a happy mood are motivated to systematically process the message.

Significant evidence regarding the interactive effects of self-referencing and mood on information processing has remained lacking. The current study provides support that it is a motivational deficit that prevents happy people from systematic processing, and not one cognitive in nature. Additionally, the results from our study provide significant evidence that self-referencing can serve as a valuable tool for persuasive message processing.

\section{Limitations and Future Directions}

The results of the current study provided evidence that self-referencing may be the motivational factor that prompts people experiencing a happy mood to systematically process persuasive messages. However, previous information processing studies measuring attitude change have used free recall of information as an additional dependent 
variable. Asking participants to write down any thoughts that come to mind related to the message serves as another measure when assessing systematic or heuristic processing. We used only attitude change as our dependent variable in the current study. By requesting that participants recall as much information about the message as possible, we could have offered further evidence that participants systematically processed the message.

Additionally, because of recent findings, future research would benefit by assessing whether the message is perceived as self-threatening or negative. By assessing whether participants perceive the information as damaging and/or self-threatening, we can identify more accurately the various sub-factors that influence individual's ability to process persuasive messages in different mood states. 


\section{References}

Asuncion, A.G. \& Lam, W.F. (1995). Affect and impression formation: Influence of mood on person memory. Journal of Experimental Social Psychology, 31, 437464.

Bargh, J (Ed.), Unintended Thought (pp. 212-252). New York: Guilford Press.

Bellezza, F.S. (1984). The self as a mnemonic device: The role of internal cues. Journal of Personality and Social Psychology, 47, 506-516.

Brown, P., Keenan, J.M., Potts, G.R. (1986). The self-reference effect with imagery encoding. Journal of Personality and Social Psychology, 51, 897-906.

Burnkrant, R.E. \& Unnava, H.R. (1989). Self-referencing: A strategy for increasing processing of message content. Personality and Social Psychology Bulletin, 15, 628-638.

Burnkrant, R.E. \& Unnava, H.R. (1995). Effects of self-referencing on persuasion. Journal of Consumer Research, 22, 17-26.

Bless, H., Bohner, G., Schwarz, N. \& Strack, F. (1990). Mood and persuasion: A cognitive response analysis. Personality and Social Psychology Bulletin, 16, 331345.

Chaiken, S. (1980). Heuristic versus systematic information processing and the use of source versus message cues in persuasion. Journal of Personality and Social Psychology, 39, 752-756. 
Chaiken, S. (1987). The heuristic model of persuasion. In M. P. Zanna, J. M. Olson and C. P. Herman (Eds.), Social influence: The Ontario symposium (Volume 5, pp. 3-39). Hillsdale, NJ: Erlbaum.

Chaiken, S., Liberman, A., \& Eagly, A.H. (1989). Heuristic and systematic information processing within and beyond the persuasion context. In J.S. Uleman \& J.A.

Chaiken, S., Wood, W., \& Eagly, A. H. (1996). Principles of persuasion. In E.T. Higgins and A. Kruglanski (Eds.), Social psychology: Handbook of basic mechanisms and processes. New York: Guilford Press.

Chen, S., Duckworth, K. \& Chaiken, K. (1999). Motivated heuristic and systematic processing. Psychological Inquiry, 10, 44-50.

Das, E. \& Fennis, B. (2008). In the mood to face the facts: When a positive mood promotes systematic processing of self-threatening information. Motivation and Emotion, 32, 221-230.

Debevec, K. \& Romeo, J.B. (1988). Self-referencing as a mediator of the effectiveness of sex-role portrayals in advertising. Psychology \& Marketing, 5, 71-84.

Debevec, K. \& Romeo, J.B. (1992). Self-referent processing in perceptions of verbal and visual commercial information. Journal of Consumer Psychology, 1, 83-102.

Ellis, H.C. \& Ashbrook, P.W. (1988). Resource allocation model of the effects of depressed mood states on memory. In K. Fiedler \& J. Forgas (Eds.), Affect, cognition, and social behaviour (pp.25-43). Toronto: Hogrefe. 
Hutton, D.G. \& Baumeister, R.F. (1992). Self-awareness and attitude change: Seeing oneself on the central route to persuasion. Personality and Social Psychology Bulletin, 18, 68-75.

Isbell, L.M. (2004). Not all happy people are lazy or stupid: Evidence of systematic processing in happy moods. Journal of Experimental Social Psychology, 40, 341350.

Isen, A.M. \& Simmonds, S. (1978). The effect of feeling good on a helping task that is incompatible with good mood. Social Psychology Quarterly, 41, 346-349.

Isen, A.M. (1984). Toward understanding the role of affect in cognition. In R. Wyer \& T. Srull (Ed.), Handbook of social cognition (pp. 179-236). Hillsdale NJ: Erlbaum.

Isen, A.M. \& Daubman, K.A. (1984). The Influence of affect on categorization. Journal of Personality and Social Psychology, 47, 1206-1217.

Isen, A.M., Ashby, G.F., Turken, A.U. (1999). A Neuropsychological theory of positive affect and its influence on cognition. Psychological Review, 106, 529-550.

Isen, A.M., Labroo, A.A., Durlach, P. (2004). An Influence of product and brand name on positive affect: Implicit and explicit measures. Motivation and Emotion, 28, 43-63.

Janis, I. \& Mann, L. (1977). Decision making: A psychological analysis of conflict, choice, and commitment. New York: The Free Press.

Liberman, A. \& Chaiken, S. (1992). Defensive processing of personally relevant health messages. Personality and Social Psychology Bulletin, 18, 669-679. 
Mackie, D.M., \& Worth, L.T. (1989). Processing deficits and the mediation of positive affect in persuasion. Journal of Personality and Social Psychology, 57, 27-40.

Mackie, D. M., Worth, L.T., Asuncion, A.G. (1990). Processing of persuasive in-group messages. Journal of Personality and Social Psychology, 58, 812-822.

Petty, R. E., \& Cacioppo, J. T. (1979). Issue involvement can increase or decrease persuasion by enhancing message-relevant cognitive processes. Journal of Personality and Social Psychology, 37, 1915-1926.

Petty, R. E. \& Brock, T.C. (1981). Thought disruption and persuasion. In R. E. Petty, T. M. Ostrorn, \& T. C. Brock (Ed.), Cognitive responsrs in Persuasion (pp. 55-79). Hillsdale, NJ: Lawrence Erlhaum.

Petty, R.E., \& Cacioppo, J.T. (1986). The elaboration likelihood model of persuasion. Advances in Experimental Social Psychology, 19, 123-205.

Petty, R.E., Wegener, D.T., Fabrigar, L.R. (1997). Attitudes and attitude change. Annual Review of Psychology, 48, 609-647.

Petty, R.E., Fleming, M.A., Priester, J.R., Feinstein, A.H. (2001). Individual versus group interest violation: Surprise as a determinant of argument scrutiny and persuasion. Social Cognition, 19, 418-442.

Raghunathan, R. \& Trope, Y. (2002). Walking the tightrope between feeling good and being accurate: mood as a resource in processing persuasive messages. Journal of Personality \& Social Psychology, 83, 510-525. 
Rogers, T.B., Kuiper, N.A. \& Kirker, W.S. (1977). Self-reference and the encoding of personal information. Journal of Personality and Social Psychology, 35, 677688.

Schwarz, N. \& Clore, G. L. (1983). Mood, misattribution, and judgments of well-being: informative and directive functions of affective states. Journal of Personality and Social Psychology, 45, 513-523.

Schwarz, N. \& Clore, G.L. (1988). How do I feel about it? Informative functions of affective states. In K. Fiedler \& J. Forgas (Ed.), Affect, cognition, and social behavior (pp. 44-62). Toronto: Hogrefe.

Schwarz, N. (1990). Feelings as information: Informational and motivational functions of affective states. In E. T. Higgins \& R. M. Sorrentino (Ed.), Handbook of motivation and cognition: Foundations of social behavior (Vol. 2; pp. 527-561). New York, NY: Guilford Press.

Schwarz, N. \& Bless, B. (1991). Happy and mindless, but sad and smart? The impact of affective states on analytic reasoning. In J.P. Forgas (Ed.), Emotion and social Judgments (pp. 55-71). London: Pergamon.

Schwarz, N., \& Clore, G.L. (1996). Feelings and phenomenal experiences. In E.T. Higgins \& A. Kruglanski (Ed.), Social psychology: Handbook of basic principles (pp. 433-465). New York: Guilford.

Sinclair, R.C, \& Mark, M.M. (1992). The influence of mood state on judgment and action: Effects on persuasion, categorization, social justice, person perception, 
and judgmental accuracy. In L. L. Martin \& A. Tesser (Ed.), The construction of social judgments (pp.165-193). Hillsdale, NJ: Erlbaum.

Sinclair, R.C., Mark, M.M., \& Clore, G. L. (1994). Mood-related persuasion depends on (mis)attributions. Social Cognition, 12, 309-326

Sinclair, R.C., Moore, S.E., Melvin, M.M., Soldat, A.S., Lavis, C.A. (2010). Incidental moods, source likeability, and persuasion: Liking motivates message elaboration in happy people. Cognition and Emotion, 24, 940-961.

Wegener, D.T., \& R.E. (1994). Mood management across affective states: The hedonic contingency hypothesis. Journal of Personality and Social Psychology 66 (1994), pp. $1034-1048$

Worth, L.T., \& Mackie, D.M. (1987). Cognitive mediation of positive affect in persuasion. Social Cognition, 5, 76-94. 
Appendix A

Pre-Attitude Scale

The following survey is being administered by another SJSU research lab and has been combined with the current research experiment. The aim of this study is to understand college students' perspectives on various public issues. This survey will ask you to rate your opinions on a list of topics. Please stop when you have completed this survey and wait for instructions about continuing on to the next experiment.

Please first answer the following questions about yourself.

Gender: Male Female

Age: $\quad$ under $18 \quad 18-19 \quad 20-21 \quad 22-23 \quad 24-25$ $26+$

Ethnicity: Caucasian

African American Latino/Chicano Asian

Other 
Please rate your level of agreement with each of the sentences as accurately as possible.

Being a vegetarian/vegan leads to better health than eating meat/animal products.

What is your opinion on this issue?

$\begin{array}{lccccc}1 & 2 & 3 & 5 & 6 & 7 \\ \begin{array}{l}\text { strongly } \\ \text { disagree }\end{array} & & \text { neutral } & \text { strongly agree }\end{array}$

How much do you know about this issue?

\begin{tabular}{|c|}
\hline${ }^{1}$ not at all knowledgeable ${ }^{2}$ \\
\hline
\end{tabular}

How important is this issue to you?

$\begin{array}{cccccccc}1 & 2 & 3 & & 5 & 6 & 7\end{array}$

Eating a low carbohydrate diet leads to better health than eating a diet where carbohydrate intake is not regulated.

What is your opinion on this issue?

$\begin{array}{lllrrr}1 & 2 & 3 & 4 & 5 & 6 \\ \text { strongly disagree } & & \text { neutral } & \text { strongly agree }\end{array}$

How much do you know about this issue?

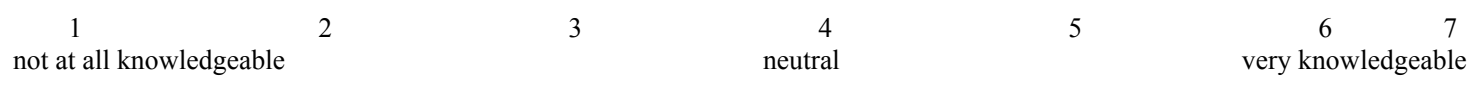

How important is this issue to you?

$\begin{array}{cccccc}1 & 2 & 3 & 4 & 5 & 6 \\ \text { not at all important } & & \text { neutral } & & \text { very important }\end{array}$

Drinking tap water is healthier than drinking bottled water.

What is your opinion on this issue?

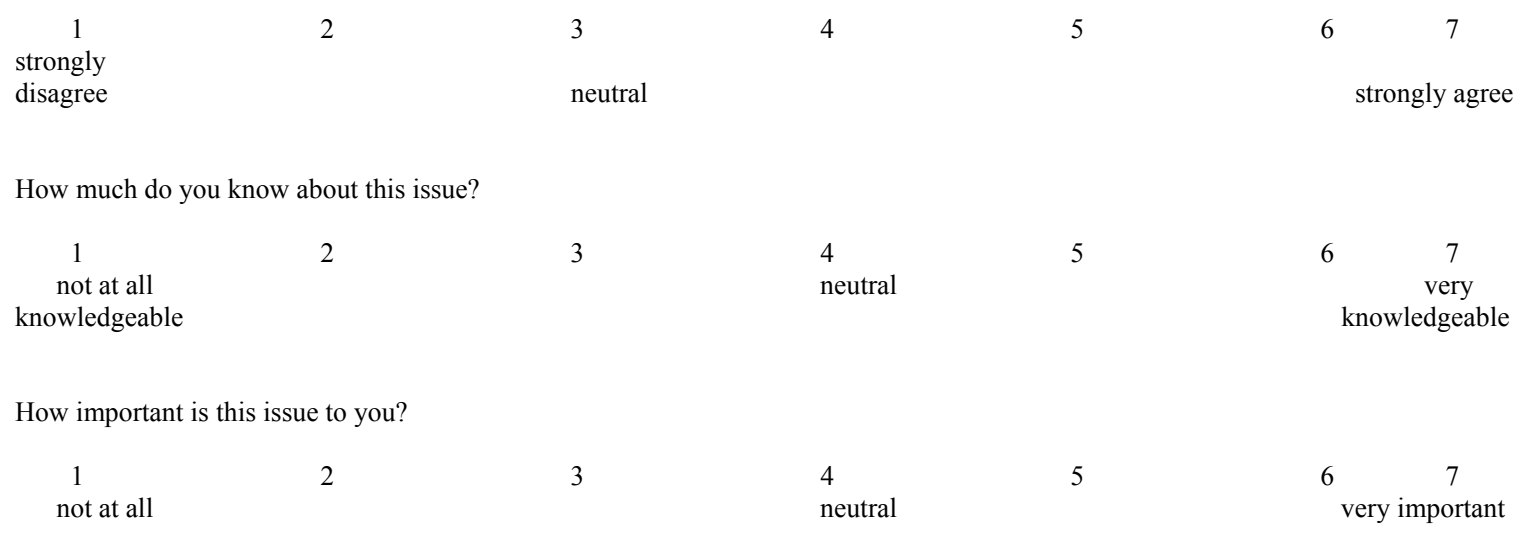


Taking herbal supplements is healthier than taking prescription medications.

What is your opinion on this issue?

$\begin{array}{cccccc}1 & 2 & 3 & 4 & 5 & 6 \\ \text { strongly disagree } & & \text { neutral } & & \text { strongly } \\ \text { agree }\end{array}$

How much do you know about this issue?

$\begin{array}{cccc}1 & 2 & 3 & 4 \\ \text { not at all } & & & \text { neutral }\end{array}$

not at all

How important is this issue to you?

1

not at all neutral
6
$\quad$ very important

Eating organic food is healthier than eating food not grown/raised using organic farming.

What is your opinion on this issue?

$\begin{array}{cccc}1 & 2 & 3 & 4 \\ \begin{array}{l}\text { strongly } \\ \text { disagree }\end{array} & & \text { neutral }\end{array}$

5

disagree

How much do you know about this issue?
2

not at all

knowledgeable

How important is this issue to you?

1

not at all

important neutral neutral
$6 \quad{ }^{7}$
very
knowledgeable 


\section{Getting a yearly flu shot is healthier than not getting a yearly flu shot.}

What is your opinion on this issue?

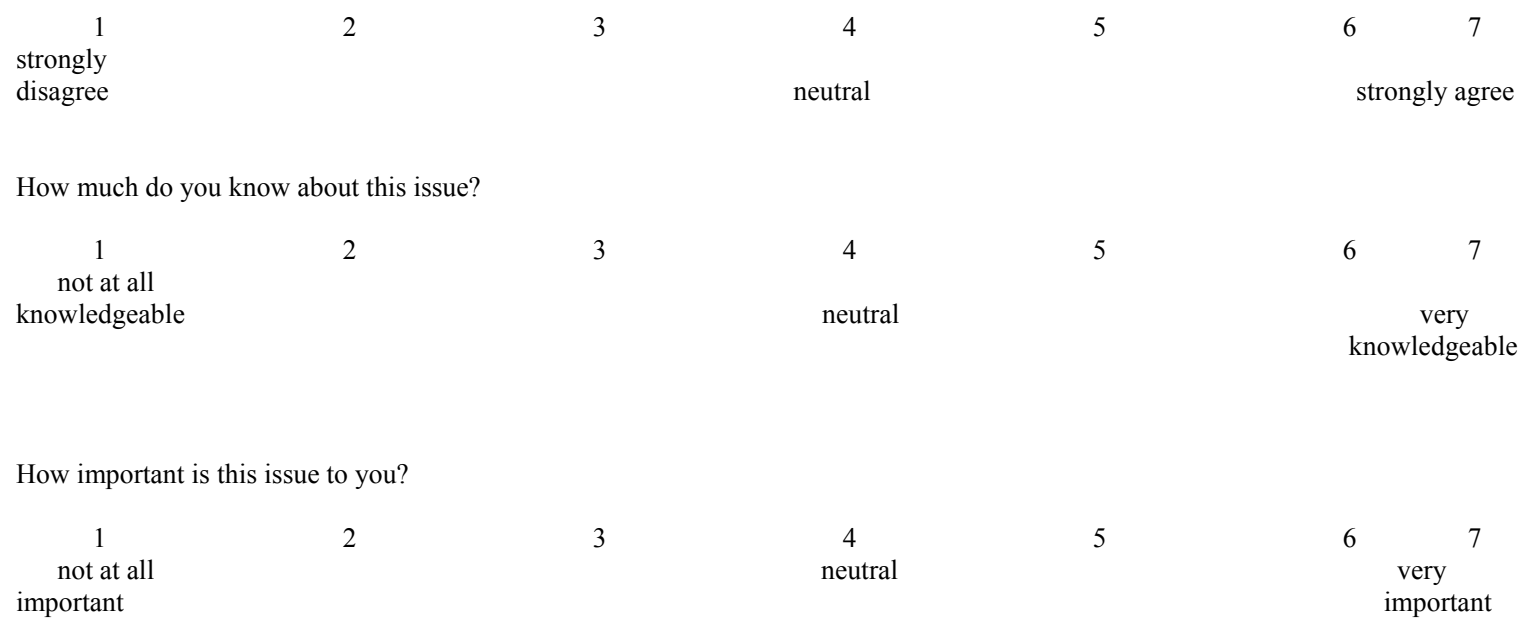


Appendix B

This lab is also pretesting some videos that will be used for another experiment next semester, which will be studying college students' opinions about the mass media. Please pay attention to the video shown and be prepared to rate your opinions on the video. Wait until the video is finished before turning the page. 
Please rate what you thought about the video and how appropriate this video would be for college students.

How did this video clip make you feel?

$\begin{array}{ccccccc}1 & 2 & 3 & 4 & 5 & 6 & 7 \\ \text { very sad } & & & \text { neutral } & & & \text { very } \\ \text { happy }\end{array}$

How interesting was this video clip?

\begin{tabular}{|c|c|c|c|c|c|c|}
\hline $\begin{array}{c}1 \\
\text { not at all } \\
\text { interesting }\end{array}$ & 2 & 3 & $\begin{array}{c}4 \\
\text { neutral }\end{array}$ & 5 & 6 & $\begin{array}{c}7 \\
\text { very } \\
\text { interesting }\end{array}$ \\
\hline & \multicolumn{6}{|c|}{ How would you describe your current feelings? } \\
\hline $\begin{array}{c}1 \\
\text { very bad }\end{array}$ & 2 & 3 & $\begin{array}{c}4 \\
\text { neutra }\end{array}$ & 5 & 6 & $\begin{array}{c}7 \\
\text { very } \\
\text { good }\end{array}$ \\
\hline
\end{tabular}

How engaging was the video clip?

$\begin{array}{ccccccc}1 & 2 & 3 & 4 & 5 & 6 & 7 \\ \begin{array}{c}\text { not at all } \\ \text { engaging }\end{array} & & & \text { neutral } & & & \begin{array}{c}\text { very } \\ \text { engaging }\end{array}\end{array}$

How suitable do you think this video clip is for use in a study with undergraduates?

$\begin{array}{ccccccc}1 & 2 & 3 & 4 & 5 & 6 & 7 \\ \begin{array}{c}\text { not at all } \\ \text { suitable }\end{array} & & & \text { neutral } & & & \begin{array}{c}\text { very } \\ \text { suitable }\end{array}\end{array}$

What is your present mood?

$\begin{array}{ccccccc}1 & 2 & 3 & 4 & 5 & 6 & 7 \\ \begin{array}{c}\text { very } \\ \text { negative }\end{array} & & & \text { neutral } & & & \text { very } \\ \text { positive }\end{array}$

How compelling was this video?

$\begin{array}{ccccccc}1 & 2 & 3 & 4 & 5 & 6 & 7 \\ \text { not at all } & & & \text { neutral } & & & \begin{array}{c}\text { very } \\ \text { much }\end{array}\end{array}$

You have completed the video pretesting section. Please stop here and wait for further instructions. 
Appendix C

Now you are ready to begin the main experiment. On the following page will be a paragraph on a topic concerning drinking water. First, answer the following questions on this page concerning your readiness for the experiment. Do not continue on to the next page until the researcher instructs you to do so.

Instructions: Please rate your agreement for each statement regarding the preceding paragraph.

How ready are you to read and answer questions about this paragraph?

$\begin{array}{ccccccc}1 & 2 & 3 & 4 & 5 & 6 & 7 \\ \begin{array}{c}\text { Not very } \\ \text { much }\end{array} & & \text { neutral } & & & \begin{array}{c}\text { Very } \\ \text { much so }\end{array}\end{array}$

Please rate your feelings right now.

$\begin{array}{ccccccc}1 & 2 & 3 & 4 & 5 & 6 & 7 \\ \text { Very sad } & & \text { neutral } & & & \begin{array}{c}\text { Very } \\ \text { happy }\end{array}\end{array}$

What kind of mood are you in right at this moment?

$\begin{array}{ccccccc}1 & 2 & 3 & 4 & 5 & 6 & 7 \\ \begin{array}{c}\text { Very } \\ \text { negative }\end{array} & & \text { neutral } & & & \begin{array}{c}\text { Very } \\ \text { positive }\end{array}\end{array}$

How relaxed are you right now?

$\begin{array}{ccccccc}1 & 2 & 3 & 4 & 5 & 6 & 7 \\ \begin{array}{c}\text { Not very } \\ \text { much }\end{array} & & & \text { neutral } & & & \text { Very } \\ \text { much so }\end{array}$

\section{$---S T O P---$ \\ DO NOT CONTINUE UNTIL THE RESEARCHER INSTRUCTS YOU TO DO SO}


Appendix D

Strong Self-Referencing

\section{Instructions: Please read the following paragraph.}

Drinking Tap Water Is Healthier Than Drinking Bottled Water

Remember the last time you bought bottled water on SJSU's campus instead of bringing tap water from your home because you thought bottled water was more pure? Before you spend your hard-earned money at SJSU's cafeteria or any other store in San Jose, you should know about research that shows tap water is actually a healthier option for you. First, the federal government does not regulate our in-state California sales, so, the FDA is prevented from ensuring the safety of $65 \%$ of bottled water you buy here in San Jose. As a result, a four-year U.S. scientific study shows that one-third of bottled water you are drinking is consistently contaminated with dangerous levels of chemicals, bacteria, and even arsenic. We have no regulations that the bottled water you buy be tested for parasites such as cryptosporidium or giardia. So, as you sit in class with your bottled water, you could be unknowingly ingesting these parasites that have been shown to damage your digestive tract. You may think you are drinking bottled water as a healthy alternative to soda, but your bottle is a source of DEHP, a cancer-causing agent. DEHP is produced in plastic bottle manufacturing and it leaks from the container into your water that you then digest. Unbelievably, the government does not require companies to minimize the amounts of DEHP in their products.

On the other hand, you are protected from this dangerous chemical when you drink tap water because the U.S. government regulates DEHP in all public water. You see, tap water is a public utility, so the city of San Jose is responsible to regulate it; thus, our San Jose health board stringently tests the water coming out of your tap at home hundreds of times per month while consumer safety boards test your bottled water only once a week. Furthermore, the government does not require bottled water companies to report many kinds of contamination that can cause you serious health threats. In contrast, the government requires serious tap water violations to be reported to you and your San Jose community within 48 hours. Finally, to ensure quality and control, the Federal EPA 
requires tap water that you drink to be tested by objective and certified laboratories while the FDA allows potentially biased private laboratories -- employed by the bottled water manufactures themselves -- to test bottled water you are drinking everyday at your home, at your school and at your work. 


\section{Weak Self-Referencing}

\section{Instructions: Please read the following paragraph.}

Drinking Tap Water Is Healthier Than Drinking Bottled Water

Remember the last time you bought bottled water on SJSU's campus instead of drinking tap water because you thought bottled water was cleaner? According to a government research project, sometimes tap water may be better for you than that bottled water you pay for at SJSU's cafeteria. As you sit in class drinking that bottled water, you may think that it can't be contaminated with anything because it tastes fresher to you. Also, you may think that since bottled water comes from a fresh mountain spring, and then is sealed and delivered to your local San Jose store, it must be automatically better for you than drinking out of your tap. However, as a college student at San Jose State, you should think twice about this because the results from research show otherwise. Tap water is constantly moving through your pipes unlike bottled water, which remain stagnant, so there is a good chance that your tap water right here in the Bay Area is better. Furthermore, do you ever hear about people in the news having health problems resulting from drinking too much tap water? Your home tap water here in San Jose just can't be that bad for you.

In addition, large amounts of bottled water you purchase here in San Jose may not really be regulated. Government health agencies that say they ensure the safety and quality of your bottled water are often very lazy. How do you know if these agencies are following through with certifications in your neighborhood? There is no way for you to know whether they are actually regulating all goods sold here in California like they say they are. Also, your home tap water is far more convenient for you than bottled water. You can store tap water in any container you have at your house and you don't have worry about carrying around a bottle because you can drink out of any public fountain on San Jose's campus, anywhere you happen to be. Finally, bottled water commercials you watch can be misleading and may actually be lying to you. There is no way for you to know if at least some of the bottled water you spend your hard earned money on is 
actually just tap water in a bottle instead of originating from some fresh water spring like you see in the pictures 


\section{Strong Non Self-Referencing}

\section{Instructions: Please read the following paragraph.}

\section{Drinking Tap Water Is Healthier Than Drinking Bottled Water}

It is a common assumption that drinking bottled water is safer than drinking tap water because bottled water is cleaner or more pure. Well, here are the real facts that show that tap water may actually be a smarter and healthier option than purchases of bottled water. To begin with, the federal government does not regulate in-state sales, so, the FDA is prevented from ensuring the safety of about $65 \%$ of the bottled water sold in the United States. According to a four-year scientific study by a U.S. government agency, one-third of tested bottled water is consistently contaminated with dangerous levels of chemicals, bacteria, and even arsenic. Another example of the health dangers that come with bottled water is that federal government regulations do not require bottled water to be tested for parasites such as cryptosporidium or giardia. Numerous studies have shown that these parasites cause major health problems including damage to the digestive tract and other organs in the body. In addition, DEHP is a cancer-causing agent that is produced in plastic bottle manufacturing. This chemical can leak from the bottle and into the water that is ingested. Unbelievably, the government does not require bottled water companies to minimize the amounts of DEHP in their products and consequently, many people could be exposed to this dangerous chemical.

On the other hand, protections from this chemical are in place with tap water because the U.S. government regulates DEHP in public water. Because tap water is a public utility, government health boards have a responsibility to regulate it; thus, these agencies stringently test tap water hundreds of times per month while consumer safety boards test bottled water only once a week. Furthermore, bottle water may have more poisons because the government does not require bottled water companies to report contamination that may cause serious health threats. In contrast, the government requires serious tap water violations to be reported to communities within 48 hours. Finally, to ensure quality and control, the Federal EPA requires tap water to be tested by objective 
and certified laboratories while the FDA allows potentially biased private laboratories -employed by the bottled water manufactures themselves -- to test bottled water. 


\section{Weak Non Self-Referencing}

\section{Instructions: Please read the following paragraph.}

\section{Drinking Tap Water Is Healthier Than Drinking Bottled Water}

According to a government research project studying the contents of bottled water versus tap water, sometimes tap water is actually cleaner and healthier than bottled water. These results may be surprising because many people think that bottled water is safer and cleaner than tap water. They think that there is no way that bottled water could be contaminated with anything because it tastes fresher and cleaner. However, just because bottled water is bottled at a fresh spring in the mountains, then sealed and delivered to stores, it is not automatically better than drinking out of a tap. People should think twice about these assumptions because research results show that tap water is better. First, there are certain times when tap water can actually be cleaner than bottled water. Tap water is constantly moving through pipes unlike bottled waters, which remain stagnant, so there is a good chance that tap water must be better. Furthermore, there are many people in the United States who drink tap water instead of bottled water. Television news programs and newspapers never talk about people having health problems resulting from drinking too much tap water. Nobody ever thinks twice about drinking out of a faucet or a fountain, but people are always checking the label to be sure bottled water is coming from a good source. Tap water just can't be that bad.

In addition, large amounts of bottled water sold in the United States may not really be regulated. Government health agencies that say they ensure the safety and quality of bottled water are often very lazy. Maybe these agencies are not following through with certifications, and there is no way to know whether they are actually regulating all goods sold in the U.S. like they say they are. Also, tap water is far more convenient than bottled water. Tap water can be stored in any container that is available and there is no need for transportation of tap water because it is readily available out of any faucet. Finally, these bottled water commercials can be misleading and may actually lie to consumers. At least some of the bottled water is probably just tap water in a bottle 
instead of originating from some fresh water mountain spring like they show in the pictures. 
Appendix E

Post Attitude Scale

Please rate your opinions on the paragraph you read about tap water and bottled water.

How would you rate the strength of this paragraph?

$\begin{array}{ccccccc}1 & 2 & 3 & 4 & 5 & 6 & 7 \\ \text { weak } & & & \text { neutral } & & & \text { strong }\end{array}$

How convincing is this paragraph?

$\begin{array}{ccccccc}1 & 2 & 3 & 4 & 5 & 6 & \begin{array}{c}7 \\ \text { not at all }\end{array} \\ \text { convincing }\end{array}$

How much does the language in this paragraph refer to "you" directly?

$\begin{array}{ccccccc}1 & 2 & 3 & 4 & 5 & 6 & 7 \\ \begin{array}{c}\text { not very } \\ \text { much }\end{array} & & \text { neutral } & & & \begin{array}{c}\text { very } \\ \text { much so }\end{array}\end{array}$

How do you feel at this moment?

$\begin{array}{ccccccc}1 & 2 & 3 & 4 & 5 & 6 & 7 \\ \text { very sad } & & & \text { neutral } & & & \begin{array}{c}\text { very } \\ \text { happy }\end{array}\end{array}$

This paragraph seemed to relate to me personally, as a student at San Jose State

University.

$\begin{array}{ccccccc}1 & 2 & 3 & 4 & 5 & 6 & 7 \\ \begin{array}{c}\text { strongly } \\ \text { disagree }\end{array} & & & \text { neutral } & & & \begin{array}{c}\text { strongly } \\ \text { agree }\end{array}\end{array}$

This paragraph addressed a general audience as opposed to people like me specifically in San Jose.

$\begin{array}{ccccccc}1 & 2 & 3 & 4 & 5 & 6 & 7 \\ \begin{array}{c}\text { Strongly } \\ \text { disagree }\end{array} & & & \text { neutral } & & & \begin{array}{c}\text { strongly } \\ \text { agree }\end{array}\end{array}$


Describe your current mood.

$\begin{array}{ccccccc}1 & 2 & 3 & 4 & 5 & 6 & 7 \\ \begin{array}{c}\text { very } \\ \text { negative }\end{array} & & & \text { neutral } & & & \text { very } \\ \text { positive }\end{array}$

\section{Continue....}

After reading the paragraph, what is your opinion on the argument that tap water is better than bottled water?

$\begin{array}{ccccccc}1 & 2 & 3 & 4 & 5 & 6 & 7 \\ \begin{array}{c}\text { stongly } \\ \text { disagree }\end{array} & & & \text { neutral } & & & \begin{array}{c}\text { strongly } \\ \text { agree }\end{array}\end{array}$

How much do you know about this issue?

$\begin{array}{ccccccc}1 & 2 & 3 & 4 & 5 & 6 & 7 \\ \text { not at all } & & & \text { neutral } & & & \begin{array}{c}\text { very } \\ \text { much }\end{array}\end{array}$

How important is this issue to you?

$\begin{array}{ccccccc}1 & 2 & 3 & 4 & 5 & 6 & 7 \\ \text { not at all } & & & \text { neutral } & & & \text { very } \\ & & & & & \text { much }\end{array}$

--STOP--- 